Human and Animal Health

Vol.59: e16150025, January-December 2016 http://dx.doi.org/10.1590/1678-4324-2016150025 ISSN 1678-4324 Online Edition

BRAZILIAN ARCHIVES OF BIOLOGY AND TECHNOLOGY

AN INTERNATIONAL JOURNAL

\title{
Osteoarthritis in horses - Part 2: a review of the intra- articular use of corticosteroids as a method of treatment
}

\author{
Maria Verônica de Souza ${ }^{1 *}$ \\ ${ }^{1}$ Universidade Federal de Viçosa, Departamento de Medicina Veterinaria, Viçosa, Minas Gerais, Brasil.
}

\begin{abstract}
The problem considered in this review is related to the frequent use of corticosteroids (COs) (i.e. steroids) in the practice of equine medicine and surgery as a therapeutic strategy in the treatment of degenerative joint disease, commonly known as osteoarthritis (OA). This disease is one of the most common among the equine musculoskeletal diseases, and is clinically characterized by pain, lameness, joint effusion at the initial stage, which usually reduces with the progression of the disease, and reduced physical performance. Although steroids are considered excellent drugs in the control of clinical signs resulting from osteoarthritis, they also influence cellular activity through activation of various signaling mechanisms. However, they can cause adverse effects when administered intraarticularly, since they are immunosuppressive drugs of many cell types. They are also incriminated as suppressors of the chondrocyte matrix synthetic activities, which may contribute to 'arthropathy by corticosteroids', which can also be associated with cumulative injury resulting from improper use (dose and frequency of application) of already damaged joints. The objective of this article is to review information about the advantages and disadvantages of intraarticular COs for treatment of the disease in horses. In addition, some important information of other species is also presented.
\end{abstract}

Key words: equine, degenerative joint disease, steroids, intra-articular drugs, treatment.

${ }^{1}$ Authors for correspondence: msouzavet@gmail.com 


\section{INTRODUCTION}

Pain and limited motion are the main reasons to perform treatment, but few therapies can effectively reduce pain and improve joint mobility. According to McIIwraith et al. (2012a), the ideal treatment must relieve pain and lameness and modify the evolution of the degenerative process. Corticosteroids, potent anti-inflammatory agents, are frequently used in the treatment of OA. However, these drugs can also have undesired effects on the articular cartilage, and even worsen the disease. Although the negative effects of COs on articular cartilage have been widely reported, steroids are still largely used for their beneficial results, such as inhibition of matrix metalloproteinase (MMP) degradation (Richardson and Dodge, 2003), increase in total glycosaminoglycans (GAGs) content, decrease in cyclooxygenase (COX) 2 mRNA levels, expression of markers such as aggrecan and type II collagen (Schaefer et al., 2009) and suppression of some inflammatory mediators related to the disease. On balance, the benefits of COs may overcome their undesirable results. However, the mechanism(s) involved in the deleterious impact of steroids on cartilage is still unclear. Some in vivo studies do not confirm the efficacy of these drugs on articular cartilage (Murray et al., 1988; Robion et al., 2001). Those studies showed that some steroids alter the cartilage matrix turnover by inhibiting the synthesis of type II procollagen and increase the aggrecan release from the cartilage (Robion et al., 2001), and also that repetitive intra-articular administration alters the mechanical integrity of the cartilage (Murray et al., 1988). Therefore, the objective of this article is to comment on the advantages and disadvantages of intra-articular steroids for osteoarthritis treatment, particularly in horses.

\section{DEVELOPMENT}

\section{Possible treatments}

Many medical therapeutic options exist for the treatment of veterinary and human OA. Nonsteroidal anti-inflammatory drugs are administered systemically or orally. Nevertheless, several medications are used intra-articularly, such as COs, hyaluronic acid (HA)/sodium hyaluronate $(\mathrm{SH})$ hyaluronate $\quad(\mathrm{HA}), \quad$ polysulfated glycosaminoglycans, sodium pentosan polysulfate, sodium chondroitin sulfate, somatostatin, N-acetyl-
D-glucosamine, radiation synovectomy, dextrose prolotherapy, keratan sulfate orgotein, saline for washout, silicone, mucopolysaccharide polysulfuric acid ester, chloroquine, lactic acid solution, amikacin, gentamicin morphine, autologous serum, platelet-rich plasma, mesenchymal stem cells derived from bone marrow or adipose stromal vascular fraction, gene therapy using IL-1 antagonists, and ethanol. In addition, studies have used a topical liposomal formulation that contains diclofenac, lyophilized products from green-lipped mussel, extracorporeal shockwave, acupuncture, magnetic field, transcutaneous electrical nerve stimulation, therapeutic ultrasound, laser therapy, manual therapy, aquatic physical therapy and nutraceuticals food suplement (Uthman et al. 2003; Caron 2005; Revenaugh 2005; Carmona et al. 2007; Frisbie et al. 2009; Goodrich and Nixon 2006; Santos et al. 2009; Lindegaard et al. 2010; Cayzer et al. 2011; Kawcak et al. 2011; Baccarin et al., 2012; McIIwraith et al. 2011, 2012a; Carmalt et al. 2012; Lamas et al. 2012; Vanderweerd et al. 2012; Frisbie et al. 2013; King et al. 2013; Neuman et al. 2013; Ferris et al. 2014; Koenig et al. 2014, de Grawn et al. 2016). The use of controlled physical activity, as a complementary treatment, possibly improves the comfort level of the horse and decreases the inflammatory process (Kerbyson et al. 2013). However, the clinical and experimental results are contradictory.

One of the main problems related to the low efficacy of the various treatments available for OA in horses is the fact that the pathophysiology of the disease is still not completely elucidated. Although pathologists define the condition structurally (Pritzker et al. 2006), epidemiologists consider physical pain in their studies (Dray and Read 2007). The clinical importance of the disease in horses stands out due to the high incidence of lameness. The animal sometimes cannot properly develop the physical activity, which may occasionally occur only after intervention with the use of medications, trimming and/or shoeing, or even after rest (McIIwraith et al. 2012b). Moreover, structural problems are also considered predisposing factors in horses, particularly in joints with high mobility, such as the metacarpophalangeal joint (Norrdin and Stover 2006; Drum et al. 2007; Neundorf et al. 2010).

\section{Corticosteroids for intra-articular treatment}

Although there are several therapeutic modalities for the treatment of $\mathrm{OA}$, the intra-articular 
administration of COs is widely used in humans (Habib et al. 2010) and animals (McIIwraith 2010) for the treatment of OA and synovitis. However, the use of steroids in joints with pre-existing synovitis increases the expression of genes related to inflammation and the activity of catabolic enzymes (MacLeod et al. 1998; Todhunter et al. 1998). Classically, these drugs exert their antiinflammatory properties by inhibiting phospholipase $\mathrm{A} 2$ by producing anti-phospholipase proteins called lipocortins (Di Rosa et al. 1984). Corticosteroids inhibit the production of prostaglandin (PG) E2; vasodilation; the margination, transmigration and accumulation of inflammatory cells, and the release of enzymes, cytokines and other mediators of inflammation. Because COs act on the metabolism of arachidonic acid, the reduction of pain (van Weeren and de Grauw 2010), as well as of synovial effusion (McIIwraith, 2010) occur quickly and effectively, with a consequent decrease in lameness (van Weeren and de Grauw, 2010). However, there is controversy regarding the intra-articular use of COs because of their adverse results in the metabolism of chondrocytes by inhibiting the synthesis of proteoglycans and changing the structure of collagen networks. In addition, steroids are important inhibitors of inflammation that act by preventing the nuclear factor-kappaB (NF-kB) signaling pathway and by controlling the genes expression of matrix, which can harm cartilage turnover (Kerbyson et al. 2013). Although inhibition of the NF-kB pathway is critical for the anti-inflammatory effect of COs (Garvican et al. 2010), it may also be unfavorable because this factor regulates the expression of inflammatory genes and extracellular matrix (expression of type II collagen and aggrecan). Therefore, NF-kB inhibition can affect the turnover of cartilage and the repair process (Kydd et al. 2007). In fact, it is a transcription factor that regulates the expression of genes that are associated with inflammation. In general, it is inactive in the cell cytoplasm (Kong et al. 2001). Once activated, this factor controls the expression of inflammatory regulators (IL-6, 8 and 10), monocyte chemotactic protein 1 (MCP-1) and granulocyte-macrophage colony-stimulating factor (GM-CSF), which in turn cause the enzymatic degradation of the extracellular matrix by MMPs 1 , 3 and 13, and degradation of the metalloproteinase domains with thrombospondin motifs (ADAMTS)4 (Marcu et al. 2010), also known as aggrecanase 1. Further fragmentation of the matrix provides antigenic determinants that stimulate the release of nitric oxide, chemokines and cytokines, and the activation of mitogen-activated protein kinases (MAPKs) (Sofat, 2009). Moreover, clinical and experimental results are also contradictory, although studies have indicated that these drugs, when administered at low doses, can interrupt cartilage degeneration processes by inhibiting both MMPs and cytokines (Caron and Genovese 2003). Steroids should be used carefully with respect to dosage and the frequency and extent of application (Goodrich and Nixon 2006), because, as previously mentioned, they are immunosuppressive drugs, inhibit proteoglycan synthesis, alter collagen structure, and suppress the biosynthetic activities of many cell types, including chondrocytes. Theses adverse outcomes can cause direct damage by inappropriate use of steroids in compromised joints (Chunekamrai et al. 1989; Neustadt 2001). In fact, studies have shown that negative impact of COs on the matrix occur if high doses are used, when the treatment is repeated continuously, or when the drugs are used in healthy joints (MacLeod et al. 1998; Todhunter et al. 1998). On the other hand, Frean et al. (2002) reported adverse responses even when low doses were administered.

Regardless, COs seem to be really effective when administered at low, non-repetitive doses. The most commonly used $\mathrm{COs}$ is triamcinolone acetonide (TA), methylprednisolone acetate (MPA) and, more rarely, betamethasone acetate (BA). Triamcinolone acetate is recommended at a chondroprotective dose of 6 to $18 \mathrm{mg}$ for highly mobile joints. Methylprednisolone should not be used on such highly mobile joints because it can lead to ankylosis at doses of 40 to $100 / 120 \mathrm{mg}$. In this regard, it is only indicated for joints with little movement (Caron and Genovese 2003). Betamethasone has a slightly shorter duration (Richardson and Dodge 2003). The dose recommended for BA is 3 to 18 $\mathrm{mg}$.

Foland et al. (1994) conducted a study in 12 horses with osteochondral fragments induced by arthroscopy in radial carpal bone of both forelimbs. One of each middle carpal joint was treated with 3.9 $\mathrm{mg}$ of the betamethasone sodium phosphate in the day 14 after lesion, which was again administered in the day 35. Saline was injected in the contralateral limb. Some horses received controlled physical activity. No differences were observed in the injured cartilage of joints treated or non-treated with the steroid. However, an in vitro study demonstrated suppression of the proteoglycan 
synthesis even when lower doses were used (Frean et al. 2002).

Herzog el al. (2014) demonstrated that the steroids TA and MPA significantly down-regulate the expression of transforming growth factor- $\beta$ (TGF$\beta) \mathrm{N} 1$ and bone morphogenetic protein (BMP) 2 and 7 by articular chondrocyte matrix synthesis and cartilage homeostasis. These proteins are fundamental to the joint and stimulate the synthesis of proteoglycans (van Beuningen et al. 1998). Erickson et al. (1997) evaluated in vitro the action of recombinant human bone morphogenetic protein-2 (rhBMP-2) on various characteristics related to the growth, differentiation and synthesis of extracellular matrix and the endogenous production of mRNA from BMP-2 and -4 . The results revealed that BMP-2 regulated chondrocyte proliferation and differentiation as well as matrix production. In addition, the response depended on cell maturation phase. The chondrocytes present in the resting zone were more vulnerable, suggesting that they are intended by BMP-2. In addition, this protein may have autocrine actions on these cells.

An in vivo study in horses showed the benefits of TA on chondrocyte metabolism (Frisbie et al. 1997). This steroid has shown the best results in horses because it lowers pain/lameness and seems to stabilize joint changes without having negative effects on the transcription of the extracellular matrix. However, its action is only of medium duration (Richardson and Dodge 2003; van Weeren and de Grauw 2010), which is a limiting factor.

Using high-performance liquid chromatography, Manfredi et al. (2012) showed that after administration of TA into the coffin joint of Quarter horses, the presence of the steroid was observed in the navicular bursa fluid six hours later. Moreover, if the radiographic damage to the navicular bone is severe, the spread of drugs to the bursa may be less efficient. In fact, in the experiment of Schaefer et al. (2009), coadministration of TA $(0.6 \mathrm{mg} / \mathrm{mL})$ and high-molecular weight SH $(2.0 \mathrm{mg} / \mathrm{mL})$ increased the total GAG content. In the same trial, these researchers also found an increase in GAG in chondrocytes from the metacarpophalangeal joints of horses treated with interleukin 1 (IL-1) when this steroid was injected alone. Triamcinolone acetonide also reduced the COX-2 mRNA levels and the expression of the some markers (aggrecan and type II collagen). According to these authors, the combination of the drugs attenuated the consequences of IL-1 on proteoglycan matrix metabolism.
The administration of COs in combination with $\mathrm{SH}$, which is a widely used protocol in the practice of equine medicine (Caron 2005), is due to the chondroprotective action of this drug (Caron 2005; Mcllwraith 2010; van Weeren and de Grauw 2010), which may reduce the possible undesirable effects of steroids (McIIwraith 2010; van Weeren and de Grauw 2010). However, controlled trials have not shown an adequate reduction of pain symptoms or the action on the cartilage matrix when used alone or in combination with SH (Doyle et al. 2005; Yates et al. 2006). Further, to date, in vitro studies have not provided sufficient data to demonstrate that COs are not potentially negative for articular cartilage.

Frisbie et al. (1997) studied the impact of TA (12 $\mathrm{mg} / \mathrm{kg}$ ) on carpal osteochondral fragmentation in equine athletes. The treatment was administered on days 13 and 27 after surgery in combination with exercise on a high-speed treadmill during six weeks. Physical activity began on day 14 . According to the authors, the steroid had adequate effects on the degree of lameness, on synovial fluid (SF) and on the morphological characteristics of the articular cartilage. Therefore, the clinical use of TA in cases of osteochondral fragmentation and OA may be beneficial therapeutically. According to some authors, HA provides longer-lasting pain relief than COs do. Moreover, it is usually an expensive drug. de Grauw et al. (2016) compared the treatment of distal joints of the fore and hindlimbs, as well as in two carpal joints of 80 horses and ponies with effusion and lameness. The joints showed at least a $50 \%$ positive response to the intra-articular anesthetic block. The animals were randomly treated with TA $(12 \mathrm{mg})$ or TA (12 $\mathrm{mg})$, in association with HA (20 mg). Additionally, the horses were subjected to controlled physical activity (walking) for three weeks. The evaluation performed three weeks after a single application of the drug, which was extended up to three months, showed the animals treated with TA had a greater reduction of lameness than those that had received the combination of TA/HA. Furthermore, the response was less effective in animals under 13 years of age. However, the study did not reveal any evidence that the combination of drugs is more efficient than using only the TA alone as a form of treatment for lameness arthrogenic origin. In humans, a review conducted by Uthman et al. (2003) from 1968 to 2002 showed that coadministration of COs and $\mathrm{SH}$ is frequently used for the intra-articular treatment of OA. 
Vanderweerd et al. (2012) conducted a systematic review using well-defined criteria to verify the response of $\mathrm{OA}$ in horses by using of nutraceuticals food supplement. The categorization, as well as the inclusion of papers occurred until December 2010, in both the English and French languages. Only five studies in the species were found, but none of them had shown a real efficacy of the product in reduction of clinical signs. Some of those authors conducted another systematic review (Vanderweerd et al., 2015) to evaluate the effect of corticosteroids in healthy joints, and with osteoarthritis/synovitis induced experimentally. The investigation was conducted in rabbits, dogs and horses, and the evaluation period was from 1965 to 2014. Only in vivo controlled studies were included. A total of 35 papers were found. In 19 cases, the survey was carried out in injured joints, being six in horses. In addition, seven out of 16 studies, including OA were identified in equine species. Data showed that MPA, in many cases, presented a harmful action on the cartilage. However, Céleste et al (2005) reported that intraarticular administration of four doses $(12 \mathrm{mg} / \mathrm{kg})$ of TA before and after (3, 5 and 7 weeks) arthrocentesis of horse's radiocarpal joints did not result in damage to the cartilage. On the other hand, according to Vanderweerd et al. (2015), the real effect of the corticosteroids in the articular cartilage to be continued controversy, because many limitations in the methodology were found. Despite the satisfactory results of TA, Céleste et al. (2005) reported that this steroid also presented a potential to alter the metabolism of cartilage, as evidenced by using biomarkers in SF of healthy horses after three doses of the drug in two-week intervals.

Methylprednisolone acetate, which is widely used in Brazil and North America, is considered effective in reducing clinical signs but does not seem to modify degenerative changes in the joint (McIIwraith et al. 2010). Lower doses (10 to $40 \mathrm{mg}$ ) than those traditionally used have demonstrated satisfactory anti-inflammatory properties, as well as preventive maintenance of a healthy joint (Todhunter et al. 1996; van Weeren and de Grauw 2010), and a long-lasting effect was obtained when these doses were used (Richardson and Dodge 2003). This steroid is only indicated for joints with little movement, such as the distal hock and proximal interphalangeal joint, when the normal condition of cartilage in these joints can no longer be restored (Céleste et al. 2005, van Weeren and de Grauw 2010).
Robion et al. (2001) used SF as a marker of cartilage metabolism in the radiocarpal joints of 10 adult horses without clinical or radiographic signs of articular disease. The MPA (60 mg) was administered in the radiocarpal joint at weeks 3,5 and 7, and aseptic arthrocentesis was performed weekly (weeks 1-13). The C-propeptide of cartilage type II procollagen and cartilage aggrecan were measured. The data showed that the repeated use of the steroid resulted in a potent inhibition of the synthesis of procollagen II and caused increased release from cartilage, of aggrecan degradation products. In the study, changes occurred in cartilage matrix turnover, which suggested a negative impact on cartilage metabolism, mainly where the joint damage was limited. Caron et al. (2013) studied the influence of MPA and TA on the "expression of selected chondrocyte genes in recombinant equine interleukin-1 $\beta$ (reIL-1 $\beta)$ stimulated articular cartilage explants". Both steroids considerably inhibited the induction of MMP 13 and COX-2 at six hours. However, they also substantially depressed TIMP-2 expression. In their study, Caron et al. (2013) also did not find any differences in chondrocytic expression between the glucocorticoids.

Murray et al. (1988) compared the biomechanical properties of intra-articular injection of MPA (100 $\mathrm{mg}, 2.5 \mathrm{~mL}$ ) as a symptomatic treatment for arthritis in carpal joint of horses associated with exercise (treadmill). Four treatments were performed at 14-day intervals. According to the authors, there were significant differences between joints treated with COs and placebo regarding the material property and thickness of cartilage intrinsic. The contralateral cartilage was treated with $2.5 \mathrm{~mL}$ of a diluent solution, and displayed an increase in compressive stiffness $(97 \%)$ and shears modulus (88\%). The placebo-treated cartilage was more permeable $(121 \%)$ and thicker $(24 \%)$ than the cartilage treated with MPA. The results demonstrated that repeated applications of intraarticular steroid injection in horses submitted to exercising, results in changes in the mechanical intangibility of the cartilage. As a consequence, may cause premature cartilage degeneration. Controlled studies have demonstrated that the beneficial results of these drugs may outweigh the disadvantages and possible risks (Goodrich and Nixon 2006; McIIwraith 2010). However, as previously mentioned, in joints, steroids should be used judiciously regarding the dose and frequency of application (Goodrich and Nixon 2006), due to 
their side effects. Thus, as reported before, it is believed that the suppressive activity on the synthesis of the chondrocyte matrix contributes to the phenomenon known as 'corticosteroid arthropathy', along with the direct damage caused by inappropriate use in affected joints (Chunekamrai et al. 1989).

Doyle et al. (2005) evaluated the use of SH (0.1, 1.0 , or $1.5 \mathrm{mg} / \mathrm{mL})$ with or without MPA $(0.05,0.5$, or $5.0 \mathrm{mg} / \mathrm{mL}$ ) in matrix catabolism in 30 healthy articular cartilage explants from the metacarpophalangeal joint of horses. Corticosteroid treatment resulted in a decrease in proteoglycan synthesis, whereas addition of SH had little effect on steroid-induced cartilage matrix catabolism. On the other hand, Franklin and Cook (2013) recommended the use of MPA in conjunction with $\mathrm{SH}$ for the treatment of chronic bilateral elbow osteoarthritis in dogs. According to the authors, although conclusions that can be drawn from their study are limited, the results provide evidence that these two types of treatment can benefit dogs that have failed management of lasting elbow OA. More importantly, no adverse reactions of treatment were noted for any patient, suggesting that intra-articular application of $\mathrm{SH}$ plus corticosteroid for the treatment of OA is safe.

An alternative to the use of steroids is the opioids morphine, especially in cases of postoperative pain. According to Kerbyson et al. (2013), the analgesic effect of these drugs when intra-articularly administered has a longer duration than COs. As noted by those authors, morphine presents an important action against lameness, articular effusion and synovial inflammatory mediators. In contrast, these medications usually provide shortterm pain relief and are thus more frequently used after surgical procedures. Veterinary and human literature mentions that aquatic therapy also has satisfactory outcomes such as reduction of pain and increased joint movement.

Studies have shown that it is possible to intervene early in post-traumatic OA, but according to McIIwraith et al. (2012b), it is still difficult to determine and identify the most appropriate time to take those steps. Animal models are considered an important complementary and substitutive option for humans in the investigation of OA pathogenesis because animal studies offer information about the pathophysiology of the disorder, allowing the development of drugs and biological markers that contribute to the diagnosis and prognosis (Aigner et al. 2010). Research with horses, considered an excellent trial model for musculoskeletal diseases (van Schie et al. 2000; Chiaradia et al. 2012), may be of value in determining the ideal treatment, considering the frequency of $\mathrm{OA}$ in the species (McIIwraith 2005; Goodrich and Nixon 2006) and the availability of well-defined experimental models of OA induction. The use of some species allows the study of early pathophysiological events, which is essential for determining treatment and for the research of new therapies (McIIwraith et al. 2012b). Because the horse is involved in occupational and sport activities, it is considered a good animal model for human articular diseases (Aigner et al. 2010). According to Chiaradia et al. (2012), data obtained from this species can "provide suggestive information for tentative biomedical extrapolations", thereby overcoming the limitations on the size of the joint and "workload that are typical of other small animal models". Therefore, in vivo and in vitro studies conducted in horses are necessary because, as mentioned, these animals are models for human joint disorders.

In view of the complex function of joints, many of the treatments performed to control the degenerative process are ineffective, and new therapies are frequently developed, many of which are based on the biochemical and biomechanical understanding of the joint. However, it is necessary to understand the dynamic reciprocity between the cartilage and other tissues that occur within the joint and the mutual interaction between each of these components. This is particularly important because signaling molecules penetrate into the cartilage not only from the subchondral bone but also from the synovial fluid, thus making each structure a functional unit (Lories and Luyten 2011). In addition, several compounds can diffuse through the cartilage from the fluid or from the subchondral bone (Schultz et al. 2011).

Early identification of $\mathrm{OA}$ is critical for the prevention of disease progression (Kamm et al. 2013). The stages include clinically silent disease, active (similar to a noninfectious inflammatory process) disease, and physical manifestation or decompensation. In practice, pain and the limitation of motion are the main causes for treatment, but few therapies effectively reduce pain and improve joint mobility (Steinmeyer and Konttinen 2006). According to van Weeren and de Grauw (2010), the basic joint biology and pathogenetic mechanisms of $\mathrm{OA}$ are quite similar within the mammalian species, and pain control in the equine orthopedic patient 
will certainly benefit directly from the research performed on behalf of its human counterpart.

\section{FINAL CONSIDERATIONS}

Several strategies have been implemented over the years in an attempt to restore the properties of injured joints. Although each of these therapies can help to alleviate the subjective symptom of pain, they do not necessarily contribute to cell repair. In fact, some of the treatments have been shown to be detrimental to the joint because they suppress and inhibit specific cellular processes that are required for articular regeneration. Other therapies have shown to contribute to healing through the stimulation of different cellular aspects involved in repair.

In horses, OA is usually treated with conventional therapies that aim to reduce joint inflammation, pain, as well as stabilizing the process. Moreover, a single therapeutic agent will not be able to promote clinical improvement and slow the progression of OA. Additionally, the use of rehabilitation and physical therapy is currently fundamental to improve animal welfare and, thus, the quality of life. It may allow the animal to continue its athletic performance. Unfortunately, to date, there is no therapy that is very effective for osteoarthritis. Therefore, conducting controlled clinical studies with a standardized design is necessary.

Undoubtedly, intra-articular corticosteroid administration may help resolve inflammation and secondary pain originating from the joint. However, although steroids have been used for many years, their consequences in the articular cartilage and synovium are still unknown. Further, controlled studies conducted to date have demonstrated that the beneficial effects of steroids may outweigh the disadvantages and possible risks.

\section{ACKNOWLEDGMENTS}

The author is grateful to CAPES, FAPEMIG and $\mathrm{CNPq}$ for the usual financial support in her research projects.

\section{REFERENCES}

Aigner T, Cook JL, Gerwin N, Glasson SS, Laverty S, Little CB, et al. Histopathology atlas of animal model systems: overview of guiding principles. Osteoarth Cart Suppl 3. 2010;18:p.S2-S6.
Baccarin RY, Machado, TS, Lopes-Moraes AP, Vieira FA, Michelacci YM. Urinary glycosaminoglycans in horse osteoarthritis. Effects of chondroitin sulfate and glucosamine. Res Vet Science. 2012;93(1):88-96.

Cayzer J, Hedderley D, Gray S. A randomised, doubleblinded, placebo-controlled study on the efficacy of a unique extract of green-lipped mussel (Perna canaliculus) in horses with chronic fetlock lameness attributed to osteoarthritis. Equine vet $J$. 2011;44(4):393-398.

Carmalt JL, Bell CD, Panizzi L, Wolker RR, Lanovaz JL, Bracamonte JL. Alcohol-facilitated ankylosis of the distal intertarsal and tarsometatarsal joints in horses with osteoarthritis. $J$ Am Vet Med Assoc. 2012;240(2):199-204.

Carmona JU, Argüelles D, Climent F, Prades M. Autologous platelet concentrates as a tretment of hrses with osteoarthritis: a preliminary pilot clinical study. J Equine Vet Sci. 2007;27(4):167-170.

Caron JP. Intra-articular injections for joint disease in horses. Vet Clin North Am Equine Pract. 2005; 21(3):559-573.

Caron JP, Gandy JC, Schmidt M, Hauptman JG, Sordillo LM. Influence of corticosteroids on interleukin-1 $\beta$ stimulated equine chondrocyte gene expression. Vet Surg. 2013;42(3):231-237.

Caron JP, Genovese RL. Principle and practices of joint disease treatment. In: Ross MW, Dyson SJ, editors. Diagnosis and Management of Lameness in the Horse. Philadelphia: Saunders Company; 2003. p. 746-764.

Céleste C, Ionescu M, Poole RA, Laverty S. Repeated intraarticular injections of triamcinolone acetonide alter cartilage matrix metabolism measured by biomarkers in synovial fluid. $J$ Orthop Res. 2005;23(3):602-610.

Chiaradia E, Pepe M, Tartaglia M, Scoppetta F, D'Ambrosio C, Renzone G, et al. Gambling on putative biomarkers of osteoarthritis and osteochondrosis by equine synovial fluid proteomics. J Proteomics. 2012;75(14):4478-4493.

Chunekamrai S, Krook LP, Lust G, Maylin GA. Changes in articular cartilage after intra-articular injections of methylprednisolone acetate in horses. Am J Vet Res. 1989;50(10):1733-1744.

de Grauw JC, Visser-Meijer MC, Lashley F, Meeus P, van Weeren PR. Intra-articular treatment with triamcinolone compared with triancinolone with hyaluronate: a randomized open-label multicentre clinical trial in 80 lame horses. Equine vet $J$. 2016;48(2):152-158.

Di Rosa M, Flower RJ, Hirata F, Parente L, Russo-Marie F. Nomenclature announcement. Anti-phospholipase proteins. Prostaglandins. 1984;28:441.

Doyle AJ, Stewart AA, Constable PD, Eurell JA, Freeman DE, Griffon DJ. Effects of sodium hyaluronate and methylprednisolone acetate on 
proteoglycan synthesis in equine articular cartilage explants. Am J Vet Res. 2005;66(1):48-53.

Dray A, Read SJ. Arthritis and pain. Future targets to control osteoarthritis pain. Arthritis Res Ther. 2007;9(3):212.

Drum MG, Kawcak CE, Norrdin RW, Park RD, McIIwraith CW, Les CM. Comparison of gross and histopathologic findings with quantitative computed tomographic bone density in the distal third metacarpal bone of racehorses. Vet Radiol Ultrasound. 2007;48(6):518-527.

Erickson DM, Harris SE, Dean DD, Harris MA, Wozney JM, Boyan BB. Recombinant bone morphogenetic protein (BMP)-2 regulates costochondral growth plate chondrocytes and induces expression of BMP2 and BMP-4 in a cell maturation-dependent manner. J Orthop Res. 1997;15(3):371-380.

Ferris DJ, Frisbie DD, Kisiday JD, McIIwraith CW, Hague, BA, Major MD. Clinical outcome after intraarticular administration of bone marrow derived mesenchymal stem cells in 33 horses with stifle injury. Vet Surg. 2014;43(3):255-265.

Foland JW, McIIwraith CW, Trotter GW, Powers BE, Lamar $\mathrm{CH}$. Effect of betamethasone and exercise on equine carpal joints with osteochondral fragments. Vet Surg. 1994;23(5):369-376.

Franklin SP, Cook JL. Prospective trial of autologous conditioned plasma versus hyaluronan plus corticosteroid for elbow osteoarthritis in dogs. Can Vet J. 2013; 54(9):881-884.

Frean SP, Cambridgem H, Lees P. Effects of antiarthritic drugs on proteoglycan synthesis by equine cartilage. J Vet Pharmacol Ther. 2002;25(4):289298.

Frisbie DD, Kawcak CE, Trotter GW, Powers BE, Walton RM, McIIwraith CW. Effects of triamcinolone acetonide on an in vivo equine osteochondral fragment exercise model. Equine vet J. 1997;29(5):349-359.

Frisbie DD, McIIwraith CW, Kawcak CE, Werpy NM, Pearce GL. Evaluation of topically administered diclofenac liposomal cream for treatment of horses with experimentally induced osteoarthritis. Am J Vet Res. 2009;70(2):210-215.

Frisbie DD, McIIwraith CW, Kawcak CE, Werpy NM. Evaluation of intra-articular hyaluronan, sodium chondroitin sulfate and N-acetyl-D-glucosamine combination versus saline $(0.9 \% \mathrm{NaCl})$ for osteoarthritis using an equine model. Vet $J$. 2013;197(3):824-829.

Goodrich LR, Nixon AJ. Medical treatment of osteoarthritis in the horse: a review. Vet J. 2006;171(1):151-169.

Habib GS, Saliba W, Nashashibi M. Local effects of intra-articular corticosteroids. Clin Rheumatol. 2010;29(4):347-356.
Herzog K., Durgam S, Stewart M. A BMP-mediated pathway of chondrocyte biosynthetic suppression by corticosteroids. Bone Joint J. 2014; 96B:327.

Kamm JL, Frisbie DD, McIIwraith CW, Orr KE. Gene biomarkers in peripheral white blood cells of horses with experimentally induced osteoarthritis. Am J Vet Res. 2013;74(1):115-121.

Kawcak CE, Frisbie DD, McIIwraith CW. Effects of extracorporeal shock wave therapy and polysulfated glycosaminoglycan treatment on subchondral bone, serum biomarkers, and synovial fluid biomarkers in horses with induced osteoarthritis. Am Vet J Res. 2011;72(6):772-779.

Kerbyson K., Davison K., Sparks H. Science-in-brief: clinical highlights from BEVA congress 2012. Equine vet J. 2013;45(2):137-140.

King MR Haussler KK Kawcak CE McIIwraith CW Reiser RF. Mechanisms of a aquatic therapy and its potential use in managing equine osteoarthritis. Equine vet Educ. 2013;25(4):204-209.

Koenig TJ, Dart AJ, Mcllwraith CW, Horadagoda N, Bell RJ, Perkins N, et al. Treatment of experimentally induced osteoarthritis in horses using an intravenous combination of sodium pentosan polysulfate, $\mathrm{N}$ acetil glucosamine, and sodium hyaluronan. Vet Surg. 2014;43(5):612-622.

Kong AN, Yu R, Hebbar V, Chen C, Owuor E, Hu R, et al. Signal transduction events elicited by cancer prevention compounds. Mutat Res. 2001;480481:231-241.

Kydd AS, Reno CR, Tsoa HW, Hart DA. Early inflammatory arthritis in the rabbit: the influence of intraarticular and systemic corticosteroids on mRNA levels in connective tissues of the knee. J Rheumatol. 2007;34(1):130-139.

Lamas LP, Edmonds J, Hodge W, Zamora-Vera L, Burford J, Coomer R, et al. Use of ethanol in the treatment of distal tarsal joint osteoarthritis: 24 cases. Equine vet J. 2012;44(4):399-403.

Lindegaard C, Thomsen MH, Larsenm S, Andersen PH. Analgesic efficacy of intra-articular morphine in experimentally induced radiocarpal synovitis in horses. Vet Anaesth Analg. 2010;37(2):171-185.

Lories RJ, Luyten FP. The bone-cartilage unit in osteoarthritis. Nat Rev. 2011;7(1):43-49.

MacLeod JN, Fubini SL, Gu DN, Tetreault JW, Todhunter RJ. Effect of synovitis and corticosteroids on transcription of cartilage matrix proteins. Am J Vet Res. 1998;59(8):1021-1026.

Manfredi JM, Boyce M, Malone ED, Anderson C, Anderson LB, Trumble TN. Steroid diffusion into the navicular bursa occurs in horses affected by palmar foot pain. Vet J. 2012;171(25):642-646.

Marcu KB, Otero M, Olivotto E, Borzi RM, Goldring MB. NF-kappaB signaling: multiple angles to target OA. Curr Drug Targets. 2010;11(15):599613. 
McIIwraith CW. Frank Milne lecture: from arthroscopy to gene therapy - 30 years of looking in joints. Proceedings of the Am Assoc Equine Pract. 2005;51:65-113.

McIIwraith CW. The use of intra-articular corticosteroids in the horse: what is known on a scientific basis? Equine vet J. 2010;42(6):563-571.

McIIwraith CW, Frisbie DD, Kawcak CE. Evaluation of intramuscularly administered sodium pentosan polysulfate for treatment of experimentally induced osteoarthritis in horses. Am J Vet Res. 2012a;73(5):628-633.

McIIwraith CW, Frisbie DD, Kawcak CE. The horse as a model of naturally occurring osteoarthritis. Bone Joint Res. 2012b;1(11):297-309.

McIIwraith CW, Frisbie DD, Kawcak CE, Fuller CJ, Hurtig M, Cruz A. The OARSI histopathology initiative: recommendations for histological assessments of osteoarthritis in the horse. Osteoarth Cart Suppl. 3. 2010;IM

McIIwraith CW, Frisbie DD, Rodkey WG, Kisiday JD, Werpy NM, Kawcak CE, et al. Evaluation of intraarticular mesenchymal stem cells to augment healing of microfractured chondral defects. Arthroscopy. 2011;27(11):1552-1561.

Murray RC, DeBowes RM, Gaughan EM, Zhu CF, Athanasiou KA. The effects of intra-articular methylprednisolone and exercise on the mechanical properties of articular cartilage in the horse. Osteoarthritis and Cartilage. 1988;6(2):106-114.

Neuman JC, Prange T, Barlow BM, Davis JL. Pharmacokinetics of tobramycin following intravenous, intramuscular, and intra-articular administration in healthy horses. J Vet Pharmacol Ther. 2013; 36(6):532-541.

Neundorf RH, Lowerison MB, Cruz AM, Thomason JJ, McEwen BJ, Hurtig MB. Determination of the prevalence and severity of metacarpophalangeal joint osteoarthritis in Thoroughbred racehorses via quantitative macroscopic evaluation. Am J Vet Res. 2010;71(11):1284-1293.

Neustadt DH. Osteoarthritis: Diagnosis and Medical/Surgical Management. 3. ed. W.B. Philadelphia: Saunders Company, 2001, 688p.

Norrdin RW, Stover SM. Subchondral bone failure in overload arthrosis: a scanning electron microscopic study in horses. J Musculoskelet Neuronal Interact. 2006;6(3):251-257.

Pritzker KP, Gay S. Jimenez SA Ostergaard K Pelletier JP Revell PA et al. Osteoarthritis cartilage histopathology: grading and staging. Osteoarthr Cartil. 2006;14(1):13-29.

Revenaugh MS. Extracorporeal shockwave therapy for treatment of osteoarthritis in the horse: clinical applications. Vet Clin North Am Equine Pract. 2005;21(3):609-625.

Richardson DW, Dodge GR. Dose-dependent effects of corticosteroids on the expression of matrix-related genes in normal and cytokine-treated articular chondrocytes. Inflamm Res. 2003;52(1):39-49.

Robion FC, Doizk B, Bourk L, Marcoux M, Ionescu M, Reiner A. Use of synovial fluid markers of cartilage synthesis and turnover to study effects of repeated intra-articular administration of methylprednisolone acetate on articular cartilage in vivo. J Orthop Res. 2001;19(2):250-258.

Santos LC, de Moraes AN, Saito ME. Effects of intraarticular ropivacaine and morphine on lipopolysaccharide-induced synovitis in horses. Vet Anaesth Analg. 2009;36(3):280-286.

Schaefer CF, Stewart AA, Durgam SS, Byron CR, Stewart MC. Effects of sodium hyaluronate and triamcinolone acetonide on glyconsaminoglucan metabolism in equine articular chondrocytes treated with interleukin-1. Am J Vet Res. 2009;70(12):1494-1501.

Schultz GS, Davidson JM, Kirsner RS, Borntein P, Herman IM. Dynamic reciprocity in the wound microenvironment. Wound Repair Regen. 2011;19(2):134-148.

Sofat N. Analysing the role of endogenous matrix molecules in the development of osteoarthritis. Int J Exp Pathol. 2009;90(5):463-479.

Steinmeyer J, Konttinen YT. Oral treatment options for degenerative joint disease: present and future. $A d v$ Drug Deliv Rev. 2006;58(2):168-211.

Todhunter RJ, Fubini SL, Vernier-Singer M, Wootton JA, Lust G, Freman KP, et al. Acute synovitis and intra-articular methylprednisolone acetate in ponies. Osteoarth Cart. 1998;6(2):94-105.

Todhunter RJ, Fubini SL, Wootton JA, Lust G. Effect of methylprednisolone acetate on proteoglycan and collagen metabolism of articular cartilage explants. $J$ Rheumatol. 1996;23(7):1207-1213.

Uthman I, Raynald J-P, Haraoui B. Intra-articular therapy in osteoarthritis. Postgrad Med J. 2003;79(934):449-453.

van Beuningen HM, Glansbeek HL, van der Kraan PM, van den Berg WB. Differential effects of local application of BMP- 2 or TGF- $\beta 1$ on both articular cartilage composition and osteophyte formation. Osteoarthr Cartil. 1998;6(5):306-317.

van Schie HTM, Bakker EM, Jonker AM, van Weeren PR. Ultrasonographic tissue characterization of equine superficial digital flexor tendons by means of gray level statistics. Am J Vet Res. 2000;61(2):210219.

van Weeren PR, de Grauw JC. Pain in osteoarthritis. Vet Clin North Am Equine Pract. 2010;26(3):619-642.

Vanderweerd J-M, Coisnon C, Clegg P, Cambier C, Pierson A, Hontoir F, et al. Systematic review of efficacy of nutraceuticals to alleviate clinical signs of osteoarthritis. J Vet Intern Med. 2012;26(3):448-456.

Vanderweerd J-M, Zhao Y, Nisolle J-F, Zhang W, Zhihong L, Clegg P, et al. Effect of corticosteroids on articular cartilage: have animal studies said 
everything? Fundam Clin Pharmacol. 2015;29(5):426-438.

Yates AC, Stewart AA, Byron CR, Ponderis HC, Kaufmann KM, Constable PD. Effects of sodium hyaluronate andmethylprednisolone acetate on proteoglycan metabolism in equine articularchondrocytes treated with interleukin-1. Am J Vet Res. 2006;67(12):1980-1986.

Received: January 15, 2016; Accepted: April 25, 2016 